\title{
Words
}

\section{Raping and making love are different concepts: so are killing and voluntary euthanasia}

\author{
Jean Davies Oxford
}

\section{Author's abstract}

The distinction between ' $k$ ill' and 'help to die' is argued by analogy with the distinction between 'rape' and 'make love to'. The difference is the consent of the receiver of the act, therefore ' $k$ ill' is the wrong word for an act of active voluntary euthanasia.

The argument that doctors must not be allowed by law to perform active voluntary euthanasia because this would recognise an infringement of the sanctity of life ('the red light principle') is countered by comparing such doctors with the drivers of emergency vehicles, who are allowed to drive through red lights.

The deliberate killing of one private citizen by another is deeply disapproved of in our society, the action defined as a crime and its perpetrator severely punished. In any discussion of the circumstances of such an act the pronouncement 'Thou shalt not kill' is confidently expected to be unanswerable, and the confidence is usually justified.

Why then do we find one group of killers, the socalled 'mercy killers', regarded with almost universal approval? In such cases the police appear reluctant to prosecute, juries to convict and judges to punish (1). Within the last three years in this country the parents who ended the life of an adult quadraplegic son were given a suspended sentence (2). A doctor who gave an unusually large morphine injection to a patient dying of cancer was found 'not guilty' of murder by a jury which brought in a perverse verdict (3). And the jailing for nine months of a middle-aged lady, who helped an elderly friend to complete her suicide, evoked a storm of protest including an editorial which concluded 'People should be allowed to die on their own terms and, as Barbara Wootton once wrote, "not those of nature's cruelty or doctors' ingenuity" '(4).

The resolution of the paradox that society claims to disapprove of all deliberate ending of human life yet clearly makes exceptions to this universal condemnation, lies in examining the word 'kill'. It implies violence but, more importantly, it implies that the one being killed objects to the process, that he/she

\section{Key words}

Voluntary euthanasia; the right to die. would choose to stay alive and is being forcibly deprived of his/her most valued possession. It is an entirely inappropriate word to use in the case of voluntary euthanasia, where the incurably ill and suffering patient asks for help to die. When this happens the patient does not usually say 'Please kill me' but 'Please help me to die', or may use such a circumlocution as 'If I were an animal you would put me to sleep'. It is the doctor who does not want to comply with this request who alters the wording and replies 'But I am not allowed to kill you'.

When I put forward this distinction in argument with a leading member of the British Medical Association (BMA) he said I was merely trying to evade the issue: 'If you end someones' life there is only one word for it, you kill them'. But in spite of his eminence and authority, which silenced me at the time, he was wrong in this instance. The English language very rarely has only one word, even for what at first sight may seem to be the same act. Consider, for example, the physiological phenomenon of sexual penetration and ejaculation. There are two most commonly-used four letter words for this act, one being rape. No one is in any doubt about what consitutes the difference between love-making and rape; it is the consent of the receiver of the act. So it seems that we do need two very different words for what may be an identical sexual act, the crucial difference being whether or not it takes place by consent.

If we now return to the semantics of voluntary euthanasia let us try replacing 'kill' by 'help to die', providing the dying person is requesting that help. When we do this many of the most emotive objections to its legalisation fade away. 'Thou shalt not help to die', for instance, loses its unarguable quality. Why not, one wants to know, if dying is the only remaining good thing that can happen to someone who is asking for such help? The argument that no doctor could respond to this request without acquiring the taint of an executioner, to himself and to the patient, also loses its force (5). There are many doctors, openly in Holland and secretly in this country, who regard giving such help to die as their last act of care for an autonomous patient (6). They are not regarded as executioners either by the patient seeking help, the relatives of that patient or they themselves. It is time 
the law in this country recognised that there is a great difference between killing and helping to die, and that it consists in the dying person's consent.

But legal luminaries still protest that it would be very dangerous to modify society's absolute ban on the deliberate ending of a (non-fetal) life. And the fact that it is widely known that many doctors do practise euthanasia, usually with impunity, does not bring the law into disrepute as some of us ordinary citizens might think. This state of affairs is, we are told, an example of 'the red light principle' ie the roads are safer with the law that we must all stop at red traffic lights, even though we know that a few people drive through them (usually with impunity). The implication of this analogy is that the doctor who breaks the law by responding to the request of an incurably ill patient for help to die is to be compared with the hooligans who drive through red traffic lights. This is not only insulting but mistaken. The heedless driver acts selfishly and possibly causes harm to other road-users; the doctor's motive is the relief of suffering and respect for his/her patient's autonomy. However, there is a small group of drivers who are allowed by law to drive through red traffic lights - it consists of those who are, in certain well-defined circumstances, driving policecars, fire-engines and ambulances. They are allowed to do this normally forbidden thing because it is recognised that, on balance, the benefit to society is greater if they are not subject to the general prohibition against driving through red lights.

So there is a precedent for a special group (in the case of voluntary euthanasia, doctors) to be given permission by society to perform an act (in this case helping an incurably ill patient to die) that is absolutely forbidden to the rest of us. As with the drivers of emergency vehicles, the action must be performed with care. The guidelines which have been used for the 0 last six years in Holland to allow doctors to practise voluntary euthanasia could be used as safeguards here. There is overwhelming support in this country for such a reform in the law (7). As we continue to ignore it we impose a dreadful burden of apprehension and suffering on those who fear, not death, but being an 'unconscionable time dying' (8).

Fean Davies BEd, is Chairman of the Voluntary Euthanasia Society. Correspondence to: 56 Marlborough $R d$, Oxford OXI 4LR.

\section{References}

(1) Sharma K M. Euthanasia in Australia. Fournal of $\vec{\infty}$ contemporary health law and politics 1986; 2: 131-153.

(2) Barnard C. Shame on our doctors. The mail on Sunday 1985 May 26.

(3) McBride M. The case of Dr Carr. Voluntary Euthanasia Society newsletter 1986; 29:1.

(4) Anonymous. [editorial] Death in Britain. The Sunday Times 1984 Dec 16.

(5) Phillips M, Dawson J. Doctors' dilemmas. Brighton, Sussex: Harvester Press, 1985; 181.

(6) Admiraal P V. Active voluntary euthanasia. Voluntaog Euthanasia Society newsletter 1985; 25.

(7) National opinion poll 4701/euthanasia: $1985 \mathrm{Feb}$.

(8) Macaulay T B. Charles II: history of England ( $\mathrm{vol} 1$ ) $184 \overline{9}$ 437. 


\section{Correspondence}

\section{Killing and voluntary euthanasia}

SIR

The examples of 'mercy killing' cited in paragraph two of the article Raping and making love are different concepts: so are killing and voluntary euthanasia (1988;14:148-149), include the following: 'a doctor who gave an unusually large morphine injection to a patient dying of cancer was found "not guilty" of murder by a jury which brought in a perverse verdict' (3).

Reference (3) is to a report by me in the Voluntary Euthanasia Society Newsletter.

This example is justified neither by my report in the newsletter nor by the facts as established in court. It contains the following errors:

1. The crime of which the doctor was acquitted was not murder, (which of course carries a mandatory sentence of life imprisonment) but attempted murder, which, in cases of mercy killing, has usually resulted in a short or non-custodial sentence.

2. (a minor point, though it played an important part in the case): The injection was not morphine but phenobarbitone.

3. Since the doctor was found not guilty and made no admission, the prosecution failed to establish that 'mercy killing' was involved. The defence plea was that the 'unusually large' injection was given in error. The reasons for the 'not guilty' verdict were not stated and are of course unknown.
4. Unlike the newsletter report, which aimed at leaving the reader to draw his or her own conclusions from the facts, the article states categorically that the doctor concerned 'was found not guilty of murder by a jury which brought in a perverse verdict'. This surely amounts to saying that the doctor was not only guilty, but that he was guilty of murdering his patient, an offence with which he was not even charged. Such an allegation, followed by the identification of the doctor by name, is not only offensive, but can hardly fail to be damaging.

There is, I am afraid, little chance of the reference to the doctor passing unnoticed, particularly in the relevant locality, where detailed reports of the trial were published daily for over a fortnight. The case must have been of particular interest to your readers, not only because the defendant was a doctor, but because the prosecution was instigated by the doctors at the local hospice, who provided most of the evidence, and were the principal witnesses for the prosecution.

It is not clear why the article draws attention to this very controversial case not only by assuming that it was necessarily an example of mercy killing, but also by mentioning the doctor by name when the other cases cited are left anonymous. In the circumstances, however, it seems particularly important that the facts should be accurately reported, and I must protest at the misleading statements in the article, especially as they are claimed to derive from my report in the newsletter.

I look forward to the publication of a correction.

\section{MRS M McBRIDE \\ 96A Ridgmount Gardens, London WC1 7AZ}

\section{Correction}

Raping and making love are different concepts: so are killing and voluntary euthanasia. Jean Davies, Fournal of Medical Ethics 1988; 14:148-149.

Mrs McBride's letter was sent to Jean Davies, for comment and as a result the lines in the first column of her paper: 'a doctor who gave an unusually large morphine injection to a patient dying of cancer was found "not guilty" of murder by a jury which brought in a perverse verdict' should be corrected as follows: 'a doctor who gave an unusually large phenobarbitone injection to a patient dying of cancer was found "not guilty" of the charge of attempted murder by a jury which brought in a perverse verdict'.

We apologise to readers for the original inaccuracies. No implication that the doctor concerned was guilty is entailed or intended by the use of the term 'perverse verdict' - only that the jury's verdict went in the opposite direction to that of the judge's summing up.

The Editor has been assured by the doctor concerned that no offence has been taken by him.

Editor 